\title{
Ligand-Free Palladium Catalytic System Supported by CNT and its Application to the Mizoroki Heck Reactions
}

\author{
Youngshin Jo, Ja Young Kim, Il-Kwon Oh, ${ }^{\dagger}$ Hyun Chul Choi, ${ }^{*}$ and Sunwoo Lee \\ Department of Chemistry and Institute of Basic Science, Chonnam National University, Gwangju 500-757, Korea \\ ${ }^{*}$ E-mail: chc12@chonnam.ac.kr (H.C.Choi),sunwoo@chonnam.ac.kr (S.Lee) \\ ${ }^{\dagger}$ School of Mechanical Systems Engineering, Chonnam National University, Gwangju 500-757, Korea \\ Received February 26, 2010, Accepted March 29, 2010
}

Key Words: Palladium, Mizoroki-Heck, CNT, Nanoparticle, Aryl halides

Palladium-catalyzed carbon-carbon bond forming reactions have been studied for decades. The most common type of this reaction is the coupling of aryl halides or pseudohalides with organometal reagents or alkene derivatives. ${ }^{1}$ Generally, these reactions are classified by the metal reagent, such as $\mathrm{Mg}, \mathrm{Sn}$, $\mathrm{B}$ and $\mathrm{Si}$, which is bonded to the carbon of the aryl group, and these reactions are named for Kumada, ${ }^{2}$ Stille, ${ }^{3}$ Suzuki ${ }^{4}$ and Hiyama $^{5}$ reactions. And the Mizoroki-Heck reaction corresponds to the coupling of aryl halides and olefin derivatives. ${ }^{6}$ Since Mizoroki and Heck's original work, numerous improvements and modifications have been reported for the catalytic system. However, most catalytic systems have focused on the development of suitable ligand systems that take into consideration the steric and electronic effects. Among them, sterically bulky phosphines, ${ }^{7}$ phosphites ${ }^{8}$ and pincer type ${ }^{9}$ and carbene type ${ }^{10}$ ligand systems have been developed and applied to produce various substituted olefins. However, the employment of ligands is less desirable in fine chemical processes because they hamper the isolation and purification steps. To address these problems, ligand-free palladium catalytic systems have been examined by a number of research groups. For example, phase transfer agents, ${ }^{11}$ aqueous systems ${ }^{12}$ and nanoparticles ${ }^{13}$ have all been considered. Among these systems, palladium-nanoparticle is one of most intensively studied methods. Recently, we prepared palladium-decorated carbon nanotubes (Pd-CNTs) by depositing $\mathrm{Pd}_{2}(\mathrm{dba})_{3}$ on thiolated multiwall carbon nanotube surfaces. ${ }^{14}$ The Pd-CNTs effectively promoted the hydrodehalogenation of aryl halides to form an 85 - 99\% of the corresponding arenes. The Pd-CNTs exhibited a higher activity than that of the reference systems such as $\mathrm{Pd}_{2}(\mathrm{dba})_{3}$ and the $\mathrm{Pd}_{2}(\mathrm{dba})_{3} /$ CNT mixtures. These results indicated that the CNTs significantly influenced the catalytic activities of CNT-supported metal catalysts for carbon coupling reactions.

Several reports have used CNT-supported Pd nanoparticles as the catalyst in the Mizoroki-Heck reaction. ${ }^{15}$ However, they have some drawbacks such as high catalytic loading and exhibited only one or two examples in the coupling reaction. To the best of knowledge, the coupling of a variety of aryl halides has never been exhibited in the Pd-CNT catalyzed Mizoroki-Heck reaction. In this study, $\mathrm{Pd}(\mathrm{dba})_{2}-\mathrm{CNT}$ was synthesized from $\mathrm{Pd}(\mathrm{dba})_{2}$ based on the previous results, and the $\mathrm{Pd}(\mathrm{dba})_{2}-\mathrm{CNT}$ was applied to a variety of aryl halides in the Mizoroki-Heck reaction.
In order to expand the scope of $\mathrm{Pd}(\mathrm{dba})_{2}-\mathrm{CNT}$ to the palladium-catalyzed coupling reaction such as the Mizoroki-Heck reaction, the $\mathrm{Pd}(\mathrm{dba})_{2}$-CNT nanocomposites were synthesized by depositing $\mathrm{Pd}(\mathrm{dba})_{2}$ onto the thiolated multiwall carbon nanotube surfaces, using the method that was described in ref 14 . $\mathrm{Pd}(\mathrm{dba})_{2}$ was prepared according to the previous method, ${ }^{16}$ and $\mathrm{NaSH}$ was used to produce the thiol groups on the CNT surfaces. The thiolation was confirmed using the XPS spectrum in the sulfur $2 p$ region. The relative surface atomic ratio was estimated from the corresponding XPS peak areas, corrected with the tabulated sensitivity factors. The estimated value of the $\mathrm{S}$ content is about 2.7 atomic $\%$. The XPS data also confirmed the presence of $\mathrm{Pd}$ in the nanocomposites. The $\mathrm{Pd}$ content is estimated to be about 2.0 atomic $\%$.

First, the Mizoroki-Heck coupling reaction of 4-iodotoluene and $n$-butyl acrylate was carried out using $\mathrm{Pd}(\mathrm{dba})_{2}-\mathrm{CNT}$ and $\mathrm{Pd}_{2}(\mathrm{dba})_{3}-\mathrm{CNT}$ with $\mathrm{K}_{3} \mathrm{PO}_{4}$ as the base and DMF as the solvent. When $0.2 \mathrm{~mol} \%$ palladium catalyst was loaded, $\mathrm{Pd}(\mathrm{dba})_{2}-\mathrm{CNT}$ catalyst afforded the desired product with $98 \%$ yield, and $\mathrm{Pd}_{2}$ (dba) ${ }_{3}-\mathrm{CNT}$ catalyst exhibited $96 \%$ yield (Scheme 1 ). These dibenzylideneacetone ( $\mathrm{dba}$ ) coordinated palladium complexes are the most common palladium(0) source in the coupling reactions. It has been reported that $\mathrm{Pd}_{2}(\mathrm{dba})_{3}$ showed higher catalytic activity than $\mathrm{Pd}(\mathrm{dba})_{2}$ under the ligand free condition, ${ }^{17}$ suggesting that increasing the global concentration of dba decreased the catalytic activity. However, different reactivities were not observed between $\mathrm{Pd}(\mathrm{dba})_{2}-\mathrm{CNT}$ and $\mathrm{Pd}_{2}(\mathrm{dba})_{3}-\mathrm{CNT}$ in the Mizoroki-Heck reaction, and this catalyst exhibited good activities under the ligand-free catalytic system. Therefore, dba did not crucially affect catalytic activity in the CNT supported palladium catalyst system.

Next, the catalytic activity of $\mathrm{Pd}(\mathrm{dba})_{2}-\mathrm{CNT}$ was investigated for the coupling of 4-iodotoluene and $n$-butyl acrylate, and compared to other palladium catalytic systems, such as $\mathrm{Pd}(\mathrm{dba})_{2}$ and the mixture of CNT and $\operatorname{Pd}(\mathrm{dba})_{2}$. As shown in Figure 1,

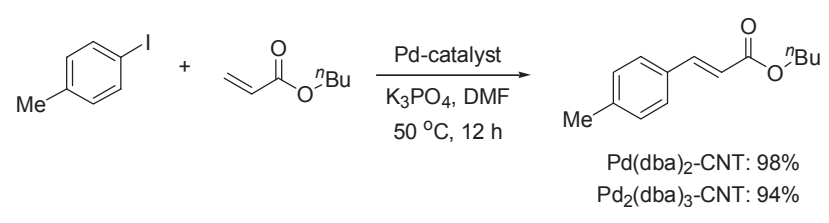

Scheme 1. Pd-catalyzed Mizoroki-Heck reaction 


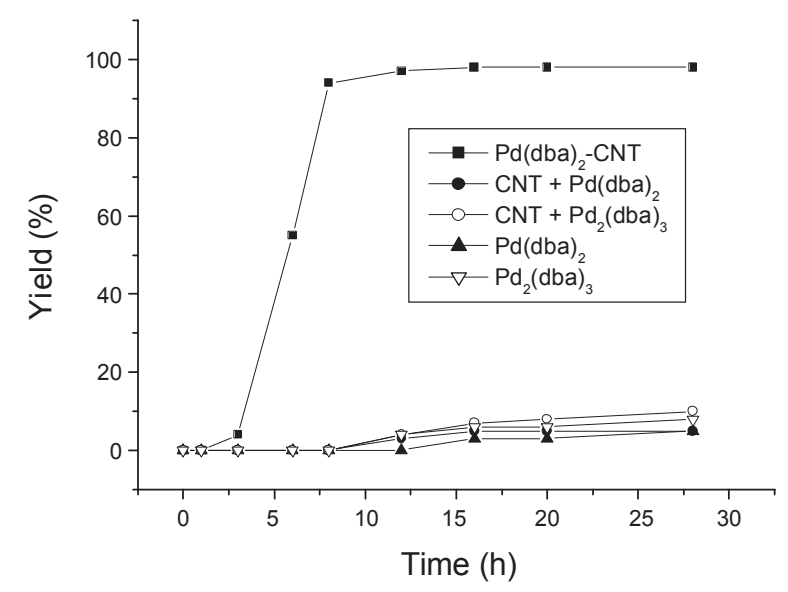

Figure 1. Palladium-catalyzed Mizoroki-Heck reactions using a variety of palladium sources.

Table 1. The Mizoroki-Heck coupling of aryl iodides and alkenes using $\mathrm{Pd}(\mathrm{dba})_{2}-\mathrm{CNT}^{a}$

$$
\begin{aligned}
& \mathrm{Ar}-\mathrm{I}+ح_{\mathrm{R}} \stackrel{\mathrm{Pd}(\mathrm{dba})_{2}-\mathrm{CNT}}{\mathrm{K}_{3} \mathrm{PO}_{4}, \mathrm{DMF}} \mathrm{Ar} \sim \mathrm{Cr}_{\mathrm{R}} \\
& \mathrm{R}=\mathrm{CO}_{2}{ }^{\mathrm{B}} \mathrm{Bu}, \mathrm{Ph}
\end{aligned}
$$

\begin{tabular}{|c|c|c|c|}
\hline Entry & ArI & $\mathrm{R}^{b}$ & Yield (\%) \\
\hline 1 & & $\mathrm{CO}_{2}{ }^{n} \mathrm{Bu}$ & 95 \\
\hline 2 & & $\mathrm{Ph}$ & 90 \\
\hline 3 & & $\mathrm{CO}_{2}{ }^{n} \mathrm{Bu}$ & 85 \\
\hline 4 & & $\mathrm{Ph}$ & 93 \\
\hline 5 & & $\mathrm{CO}_{2}{ }^{n} \mathrm{Bu}$ & 95 \\
\hline 6 & & $\mathrm{Ph}$ & 90 \\
\hline 7 & & $\mathrm{CO}_{2}{ }^{n} \mathrm{Bu}$ & 88 \\
\hline 8 & & $\mathrm{CO}_{2}{ }^{n} \mathrm{Bu}$ & 72 \\
\hline 9 & & $\mathrm{Ph}$ & 91 \\
\hline 10 & & $\mathrm{CO}_{2}{ }^{n} \mathrm{Bu}$ & 95 \\
\hline 11 & & $\mathrm{Ph}$ & 85 \\
\hline 12 & & $\mathrm{CO}_{2}{ }^{n} \mathrm{Bu}$ & 49 \\
\hline 13 & 0 & $\mathrm{Ph}$ & 23 \\
\hline 14 & & $\mathrm{Ph}$ & 86 \\
\hline
\end{tabular}

${ }^{a}$ Reaction condition: ArI (3.0 mmol), olefin (3.3 mmol), Pd(dba) $)_{2}-\mathrm{CNT}$ $(30 \mathrm{mg}, \sim 0.2 \mathrm{~mol} \%), \mathrm{K}_{3} \mathrm{PO}_{4}(4.5 \mathrm{mmol})$ was reacted in DMF for $12 \mathrm{~h}$. ${ }^{b}$ Reaction temperature $50{ }^{\circ} \mathrm{C}$ for $n$-butyl acrylate, $70{ }^{\circ} \mathrm{C}$ for styrene. ${ }^{c}$ Isolated yields, and all compounds are characterized by comparing the ${ }^{1} \mathrm{H}$ NMR and ${ }^{13} \mathrm{C}$ NMR spectra with authentic samples or literature data.
$\mathrm{Pd}(\mathrm{dba})_{2}-\mathrm{CNT}$ afforded the desired coupled product with a yield of $98 \%$ after $12 \mathrm{~h}$. However, the other palladium catalytic systems resulted in very product yields.

Having successfully demonstrated the catalytic activity of $\mathrm{Pd}(\mathrm{dba})_{2}-\mathrm{CNT}$ in the Mizoroiki-Heck reaction, we then applied this catalytic system to a variety of aryl iodides. The following reaction condition was used: 1 eq. of aryl iodide, 1.2 eq. of $n$-butyl acrylate or styrene, 2 eq. of $\mathrm{K}_{3} \mathrm{PO}_{4}$ and catalytic amount of $\mathrm{Pd}(\mathrm{dba})_{2}-\mathrm{CNT}(0.2 \mathrm{~mol} \% \mathrm{Pd})$ were reacted in DMF for $12 \mathrm{~h}$. The results are summarized in Table 1. Most of the aryl iodides that were tested produced the corresponding desired coupled product with high yields, whereas the coupling of 2-iodotoluene with $n$-butyl acrylate showed a slightly lower yield than other reactions. Unfortunately, 4-iodo acetophenone afforded unsatisfactory yields of the desired product (49\% and $23 \%$, respectively). However, meta-iodoanilsole was coupled with $n$-butyl acrylate to give the desired product with $84 \%$ yield.

This study attempted to expand the scope of the substrates to aryl bromides for the Mizoroki-Heck reactions (Table 2). The neutral and electron donating substituted aryl bromides showed moderate to low yields (entries 1-4). Especially, the sterically demanding substrate such as bromomesitylene was coupled with $n$-butyl acrylate to produce a yield of $11 \%$ (entry 4 ). However, the coupling of ortho-substituted 2-bromobiphenyl with both $n$-butyl acrylate and styrene showed good yields. The meta-substituted aryl bromides afforded good yields except for $m$-bromoanilsole, which contains an electron donating group. (entries 7-10). Both 1- and 2-bromonaphthalene showed good yields. The coupling of $n$-butyl acrylate with methyl 4-bromobenzoate and 4-bromobenzaldehyde produced yields of 68 and $61 \%$, respectively (entries 14 and 15 ). We found that aryl bromides having an electron withdrawing group produced higher yields than the aryl bromides that contained an electron donating group, which is the general reaction trend in the coupling reaction of aryl halides. The hetroaromatic bromides such as 3-bromopyridine and 2-bromothiophene showed good yields. However, 2-bromo pyridine produced a low yield of the desired product when coupled with $n$-butyl acrylate (entries 16-18).

All of the Mizoroki-Heck reactions exhibited good yields even though they were carried out in air atmosphere. Therefore, the $\mathrm{Pd}(\mathrm{dba})_{2}-\mathrm{CNT}$ catalytic system effectively promoted the carbon coupling reactions at low Pd content $(\sim 0.2 \mathrm{~mol} \%)$ in the absence of any ligands, and the system was stable toward air and moisture. Figure 2 shows a typical TEM image of Pd-CNT nanocomposites. The $\mathrm{Pd}(\mathrm{dba})_{2}$ precursors are anchored to the surface of the CNTs due to their interaction with the free electron pairs of the $\mathrm{S}$ atoms. The aggregation of anchored $\mathrm{Pd}(\mathrm{dba})_{2}$ leads to the formation of nanosized $\mathrm{Pd}(\mathrm{dba})_{2}$ clusters, which denoted as Pd nanoparticles in this study. As shown in Figure 2, the Pd nanoparticles were highly dispersed on the CNTs, preventing from the formation of low reactive palladium black, ${ }^{18}$ which may be attributed to good catalytic activity of the nanoparticles in the Mizoroki-Heck reactions.

In conclusion, CNT-supported palladium nanoparticles synthesized from $\mathrm{Pd}(\mathrm{dba})_{2}$ and the functionalized CNT. We employed $\mathrm{Pd}(\mathrm{dba})_{2}-\mathrm{CNT}$ as catalyst in the Mizoroki-Heck reactions. Aryl iodides and bromides were successfully coupled with olefins, such as $n$-butyl acrylate and styrene under ligand 
Table 2. The Mizoroki-Heck coupling of aryl bromides and alkenes using $\mathrm{Pd}(\mathrm{dba})_{2}-\mathrm{CNT}^{a}$

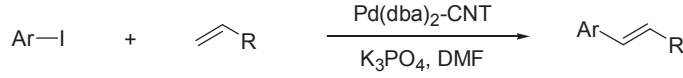

$$
\begin{aligned}
& \mathrm{R}=\mathrm{CO}_{2}{ }^{n} \mathrm{Bu}, \mathrm{Ph}
\end{aligned}
$$

\begin{tabular}{|c|c|c|c|}
\hline Entry & $\mathrm{ArBr}$ & $\mathrm{R}$ & Yield(\%) \\
\hline 1 & & $\mathrm{CO}_{2}{ }^{n} \mathrm{Bu}$ & 35 \\
\hline 2 & & $\mathrm{Ph}$ & 75 \\
\hline 3 & & $\mathrm{CO}_{2}{ }^{n} \mathrm{Bu}$ & 21 \\
\hline 4 & & $\mathrm{CO}_{2}{ }^{n} \mathrm{Bu}$ & 11 \\
\hline 5 & & $\mathrm{CO}_{2}{ }^{n} \mathrm{Bu}$ & 56 \\
\hline 6 & & $\mathrm{Ph}$ & 65 \\
\hline 7 & & $\mathrm{CO}_{2}{ }^{n} \mathrm{Bu}$ & 60 \\
\hline 8 & & $\mathrm{Ph}$ & 82 \\
\hline 9 & Me & $\mathrm{CO}_{2}{ }^{n} \mathrm{Bu}$ & 25 \\
\hline 10 & & $\mathrm{CO}_{2}{ }^{n} \mathrm{Bu}$ & 67 \\
\hline 11 & & $\mathrm{CO}_{2}{ }^{n} \mathrm{Bu}$ & 64 \\
\hline 12 & & $\mathrm{Ph}$ & 95 \\
\hline
\end{tabular}

13<smiles>Brc1ccc2ccccc2c1</smiles>

$\mathrm{CO}_{2}{ }^{n} \mathrm{Bu}$

14<smiles>CC(=O)c1ccc(Br)cc1</smiles>

$\mathrm{CO}_{2}{ }^{n} \mathrm{Bu}$

15<smiles>O=Cc1ccc(Br)cc1</smiles>

$\mathrm{CO}_{2}{ }^{n} \mathrm{Bu}$

16<smiles>Brc1cccnc1</smiles>

$\mathrm{CO}_{2}{ }^{n} \mathrm{Bu}$<smiles>Brc1ccccn1</smiles>

$\mathrm{CO}_{2}{ }^{n} \mathrm{Bu}$

18

$\left\langle{ }_{\mathrm{S}} \mathrm{CO}_{\mathrm{Br}}{ }^{n} \mathrm{Bu}\right.$

${ }^{a}$ Reaction condition: ArI (3.0 mmol), olefin (3.3 mmol), Pd(dba) ${ }_{2}-\mathrm{CNT}$ $(30 \mathrm{mg}, \sim 0.2 \mathrm{~mol} \%), \mathrm{K}_{3} \mathrm{PO}_{4}(4.5 \mathrm{mmol})$ was reacted in DMF for $12 \mathrm{~h}$ at $140{ }^{\circ} \mathrm{C} .{ }^{b}$ Isolated yields, and all compounds are characterized by comparing the ${ }^{1} \mathrm{H}$ NMR and ${ }^{13} \mathrm{C}$ NMR spectra with authentic samples or literature data.

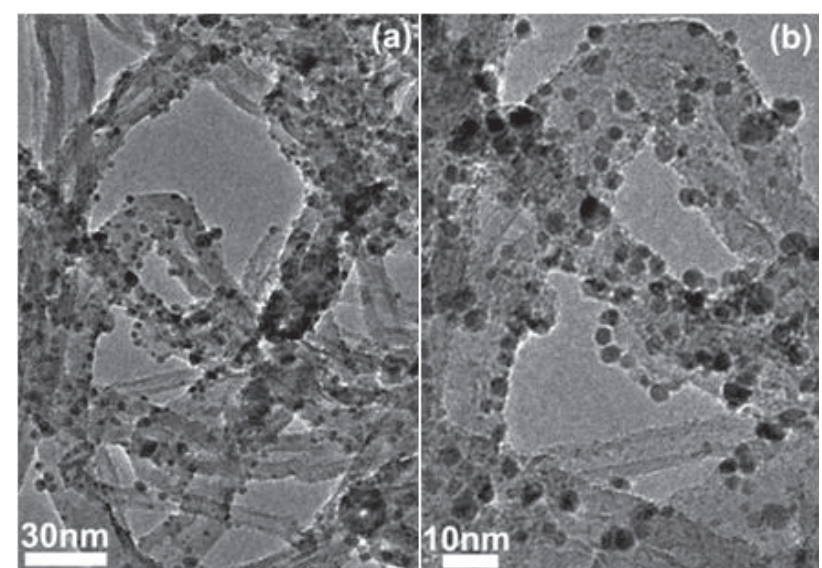

Figure 2. TEM images of the CNT-Pd nanocomposite at low magnification (a) and at high magnification (b).

free conditions. To the best of knowledge, this report is the first application of $\operatorname{Pd}(\mathrm{dba})_{2}-\mathrm{CNT}$ to a variety of aryl halides, and good reactivities were exhibited.

\section{General Experimental}

$\operatorname{Pd}(\mathrm{dba})_{2}$-CNT (30 mg, Pd base - $0.2 \mathrm{~mol} \%$ ) and 4-iodotoluene $(654.1 \mathrm{mg}, 3.0 \mathrm{mmol})$ and $n$-butyl acrylate $(423.0 \mathrm{mg}$, $3.3 \mathrm{mmol})$ were combined with $\mathrm{K}_{3} \mathrm{PO}_{4}(955.2 \mathrm{mg}, 4.5 \mathrm{mmol})$ in a small round-bottomed flask. Dimethylformamide (DMF, $15.0 \mathrm{~mL}$ ) was added and the flask was sealed with a septum. The resulting mixture was placed in an oil bath at $50^{\circ} \mathrm{C}$ for $12 \mathrm{~h}$. The reaction mixture was poured into $30 \mathrm{~mL}$ of $5 \%$ aqueous $\mathrm{LiCl}$ and extracted with $(3 \times 20 \mathrm{~mL}) \mathrm{Et}_{2} \mathrm{O}$. The combined ether extracts were washed with brine $(60 \mathrm{~mL})$, dried over $\mathrm{MgSO}_{4}$, and filtered. The solvent was removed under vacuum, and the resulting crude product was purified by flash chromatography on the silica gel. The product was eluted with 5\% ethyl acetate in hexane.

Acknowledgments. This work was supported by National Research Foundation of Korea Grant funded by the Korean Government (2009-0072357) and the Korea Science and Engineering Foundation (KOSEF) NRL Program grant funded by Korea government (MEST) (No. R0A-2008-000-20012-0).

\section{Reference}

1. de Meijer, A., Diederich, F., Eds.; Metal-Catalyzed Cross-Coupling Reactions, 2nd ed.; Vol. 1 and 2, Wiley-VCH: 2004.

2. (a) Tamao, K.; Sumitani, K.; Kumada, M. J. Am. Chem. Soc. 1972, 94, 4374-4376. (b) Tamao, K. J. Organomet. Chem. 2002, 653, 23-26.

3. (a) Milstein, D.; Stille, J. K. J. Am. Chem. Soc. 1978, 100, 36363638. (b) Farina, V.; Krishnamurthy, V.; Scott, W. J. The Stille Reaction; Wiley: New York, 1998.

4. (a) Miyaura, N.; Yanagi, T.; Suzuki, A. Tetrahedron Lett. 1979, 20,3437-3440. (b) Miyaura, N. J. Organomet. Chem. 2002, 653, 54-57.

5. (a) Hatanaka, Y.; Hiyama, T. J. Org. Chem. 1988, 53, 920-923. (b) Denmark, S. E.; Sweis, R. F. Acc. Chem. Res. 2002, 35, 835-846. 
6. (a) Mizoroki, T.; Mori, K.; Ozaki, A. Bull. Soc. Chem. Jpn. 1971, 44, 581-584. (b) Heck, R. F.; Nolley, J. P. Jr. J. Org. Chem. 1972, 37, 2320-2322. (c) Oestreich, M., Ed.; The Mizoroki-Heck Reaction; Wiley: 2009.

7. (a) Shaughnessy, K. H.; Kim, P.; Hartwig, J. F. J. Am. Chem. Soc. 1999, 121, 2123-2332. (b) Ehrentraut, A.; Zapf, A.; Beller, M. Synlett 2000, 1589-1592.

8. Beller, M.; Zapf, A. Synlett 1998, 792-793.

9. Weck, M.; Jones, C. W. Inorg. Chem. 2007, 46, 1865-1875.

10. (a) Herrmann, W. A. Angew. Chem. Int. Ed. 2002, 41, 1290-1309. (b) Karimi, B.; Enders, D. Org. Lett. 2006, 8, 1237-1240.

11. (a) Jeffery, T. Tetrahedron 1996, 52, 10113-10130. (b) Gurtler, G.; Buchwald, S. L. Chem. Eur. J. 1999, 5, 3107-3112.

12. (a) Beletskaya, I. P. Pure Appl. Chem. 1997, 69, 471-476. (b) Zhang, Z.; Zha, Z.; Gan, C.; Pan, C.; Zhou, Y.; Wang, Z.; Zhou, M.-M. J. Org. Chem. 2006, 71, 4339-4342.

13. (a) de Vries, A. H. M.; Parlevliet, F. J.; van de Vondervoort, L. S.; Mommers, J. H. M.; Henderickx, H. J. W.; Walet, M. A. M.; de
Vries, J. G. Adv. Synth. Catal. 2002, 344, 996-1002. (b) Baruwati, B.; Guin, D.; Manorama, S. V. Org. Lett. 2007, 9, 5377-5380. (c) Nikbin, N.; Ladlow, M.; Ley, S. V. Org. Process Res. Dev. 2007, 11, 458-462.

14. Kim, J. Y.; Jo, Y.; Lee, S.; Choi, H. C. Tetrahedron Lett. 2009, 50 , 6290-6292.

15. (a) Reetz, M. F.; Westermann, E. Angew. Chem. Int. Ed. 2000 , 39, 165-168. (b) Corma, A.; Garcia, H.; Leyva, A. J. Mol. Catal. A 2005, 230, 97-105. (c) Yoon, B.; Wai, C. M. J. Am. Chem. Soc. 2005, 127, 17174-17175. (d) Park, M. J.; Lee, S.-g. Bull. Korean Chem. Soc. 2007, 28, 1925-1926. (e) Karousis, M.; Tsotsou, G.-E.; Evangelista, F.; Rudolf, P.; Ragoussis, N.; Tagmatarchis, N. J. Phys. Chem. C 2008, 112, 13463-13469.

16. Rettig, M. F.; Maitlis, P. M. Inorg. Synth. 1990, 28, 110-111.

17. Fairlamb, I. J. S.; Kapdi, A. R.; Lee, A. F.; McGlacken, G. P.; Weissburger, F.; de Vries, A. H. M.; Schmieder-van de Vonderwoort, L. Chem. Eur. J. 2006, 12, 8750-8761.

18. Reetz, M. T.; de Vries, J. G. Chem. Comm. 2004, 1559-1563. 